\title{
Mesocyclone Evolution and Differences between Isolated and Embedded Supercells
}

\author{
Xiuguang Diao ${ }^{1 *}$, Qian Shi ${ }^{1}$, Houfu Zhou ${ }^{2}$ \\ ${ }^{1}$ Shandong Provincial Meteorological Observatory, Jinan, China \\ ${ }^{2}$ Anhui Institute of Meteorological Sciences, Hefei, China \\ Email: *radardxg@126.com
}

Received April 11, 2013; revised May 15, 2013; accepted May 23, 2013

Copyright (C) 2013 Xiuguang Diao et al. This is an open access article distributed under the Creative Commons Attribution License, which permits unrestricted use, distribution, and reproduction in any medium, provided the original work is properly cited.

\begin{abstract}
A total of 61 supercells with mesocyclones lasting for at least 6 volume scans were investigated. These storm parameters and mesocyclone parameters were counted and compared to determine the salient differences between isolated supercells and embedded supercells in different regions. The results showed that the mesocyclone parameters had different evolution characteristics in three stages of mesocyclone. The storm parameters, mesocyclone parameters and severe weather phenomenon had significantly differences between isolated supercells and embedded supercells. The mesocyclone parameter differences determined the differences in the reflectivity structure and weather phenomenon. The higher base and top of mesocyclone for isolated supercells indicated that the isolated supercells had higher maximum reflectivity, maximum reflectivity height, cell-based vertically integrated liquid and top of storm cell, and significantly higher probability of hail or large hail than the embedded supercells. The descending lower base of mesocyclone at its mature stage in the region of Jianghuai Plain indicated that the supercells in this region had a higher probability of mesocyclone-induced tornado.
\end{abstract}

Keywords: Evolution; Differences; Mesocyclones; Isolated and Embedded Supercells

\section{Introduction}

A supercell thunderstorm, which was originally defined by Browning $[1,2]$, is a thunderstorm that is characterized by the presence of a mesocyclone. Supercell thunderstorms are perhaps the most violent of all thunderstorm types, and are capable of producing damaging winds, large hail, weak-to-violent tornadoes, and flash flooding with severe economic losses [3-5]. The definition of a mesocyclone was as given by Burgess [6] and included criteria on the shear value, the depth of the circulation, and its temporal continuity. A mesocyclone is a strong, rotating updraft found within a powerful thunderstorm. A typical mesocyclone is 2 to 6 miles across. A mesocyclone forms within a thunderstorm as a result of wind shear, or a change in wind speed and direction with altitude.

Since the advent of the WSR-88D Doppler radar, a suite of severe weather detection algorithms such as storm cell identification and tracking (SCIT) algorithm [7] and mesocyclone detection algorithm (MDA) [8,9], has had a positive impact on severe storm detecting and

"Corresponding author. severe weather forecasting. A full description of the build 9 WSR-88D mesocyclone algorithm (B9MA) processing was described by Tipton et al. The B9MA searches for cyclonic azimuthal shear patterns (pattern vectors) in Doppler velocity data. Momentum and shear values are calculated for each pattern vector as follows:

$$
\begin{aligned}
& \text { Momentum }=\mid \text { Vin }- \text { Vout } \mid \\
& \times(\text { Distance between Vin and Vout }) \text {, and } \\
& \text { Shear }=\mid \text { Vin }- \text { Vout } \mid
\end{aligned}
$$$$
\text { /(Distance between Vin and Vout) }
$$

where Vin and Vout are maximum base velocity values toward and away from the radar, respectively. Momentum and shear values are compared to the following adaptable parameters: threshold high momentum (540 $\left.\mathrm{km}^{2} \cdot \mathrm{h}^{-1}\right)$ and low shear $\left(7.2 \mathrm{~h}^{-1}\right)$, threshold high shear $\left(14.4 \mathrm{~h}^{-1}\right)$ and low momentum $\left(180 \mathrm{~km}^{2} \cdot \mathrm{h}^{-1}\right)$. Pattern vectors that pass momentum and shear tests are expected to be characteristic of mesocyclones. Two-dimensional features are formed when a minimum number of pattern vectors (adaptable parameter threshold pattern vector $(\mathrm{TPV}))$ are in close proximity to each other. Two-dimen- 
sional features are combined in the vertical to form three-dimensional features and mesocyclones are identified.

For this study, a set of 61 supercells from WSR-98D (the B9MA version of WSR-88D, manufactured by METSTAR, China) in southern part of North China Plain and the region of Jianghuai Plain, China, were chosen. Differences of severe weather, storm parameters, mesocyclone parameters were sought between different types of supercells and different regions.

\section{Method}

\subsection{Radar Data Processing}

To ensure radar product quality, WSR-98D data in Archive Level II format were post-processed by using Unit Control Position (UCP) and unified algorithm adaptable parameters. The components of meteorological algorithm in UCP most relevant to this study were WSR-98D SCIT and B9MA. All the default algorithm adaptable parameter values completely from WSR-88D system have not been adjusted in WSR-98D. The SCIT algorithm can automatically identify and track up to 100 storms each volume scan, and display some storm parameters such as the maximum reflectivity (DBZM), the maximum reflectivity height (HT), the cell-based vertically integrated liquid (C-VIL) and the top of storm cell (TOP) in storm structure product. The mesocyclone product fed by B9MA algorithm can automatically identify storm-scale vortices and display mesocyclone parameters such as the mesocyclone base (M-BASE), the mesocyclone top (MTOP), the maximum shear of mesocyclones (M-SHEAR) and the maximum shear height (M-HT), and diameter of the core mesocyclone (DIAM).

\subsection{Data Analysis Method}

Storm parameters were analyzed and compared between different supercell types and different geographical area. All supercells in this study were divided into two categories (type I and type II) based upon the radar reflectivity and two regions (region I and region II) based upon different geographic regions. Type I (isolated supercells) was defined as being isolated from any quasi-linear region of $\geq 40 \mathrm{dBZ}$ reflectivity. Type II (embedded supercells), was defined as a supercell storm embedded within a quasi-linear area of continuous reflectivity at the lowest volume scan $\geq 40 \mathrm{dBZ}$ extending over a distance greater than $50 \mathrm{~km}$ [10]. The main research areas were plain areas included southern part of North China Plain (referred to as region $I$ in this paper) and the region of Jianghuai Plain (referred to as region II in this paper). The WSR98D had lower height of radar antenna above sea level in plain areas, so can detect low-level vortices within the storm.
Mesocyclone parameters were analyzed and compared in three stages. The first stage was the first and second volume scan time accompanied by mesocyclone symbol (approximately 12 minutes).while the third stage was the last two volume scan time (approximately 12 minutes). The volume scan time between the first stage and the third stage was the second stage of mesocyclone (12 minutes at least).

The storm parameters were averaged from one volume scan associated with the first mesocyclone symbol (yellow solid circle) to the subsequent volume scan with the last mesocyclone symbol in one case, then averaged over all of the cases.

The mesocyclone parameters were averaged respectively in stage 1 , stage 2 and stage 3 in one case, then averaged respectively in their three stages over all of the cases.

\section{Samples and Examples}

\subsection{Supercell Samples}

The set of 61 data cases, originated from 7 different radar sites (JINAN, SHIJIAZHUANG, TIANJIN, PUYANG, XUZHOU, HEFEI, NANJING) and associated with mesocyclones that lasted for at least 36 minutes (continuous six volume scans), were selected in this study from 2003 to 2012. The ranges of these storms were all $30-100 \mathrm{~km}$ from the radar sites, so the sample size and data quality were not much of a problem. 7 different radars mainly distributed in southern part of North China Plain and the region of Jianghuai Plain.

There were 32 isolated supercells and 29 embedded supercells among all the 61 supercells. 15/32 of isolated supercells and 13/29 of embedded supercells distributed in region I. 17/32 of isolated supercells and 16/29 of embedded supercells distributed in region II.

\subsection{Examples}

Below were two examples of parameter calculation and low-level reflectivity feature for isolated supercell and embedded supercell.

Figure 1 showed an isolated supercell in low-level reflectivity and the trend of mesocyclone. The supercell was discrete or isolated in radar reflectivity, associated with mesocyclone from 9:53 to 11:18 (continuous 15 volume scans). The storm parameters were averaged from 9:53 to 11:18. The averaged values of DBZM, C-VIL, HT and TOP for this supercell were $61.5 \mathrm{dBZ}, 53.9 \mathrm{~kg} \cdot \mathrm{m}^{-2}, 5.8$ $\mathrm{km}$ and $9.9 \mathrm{~km}$ respectively. The first stage of mesocyclone was 9:53 and 9:59 volume scan time, while the third stage was 11:12 and 11:18 volume scan time, and the other volume scan time was the second stage. The averaged values of M-BASE and M-TOP in the three stages were $4.7,3.2,3.0$ and $6.7,7.2,7.1 \mathrm{~km}$ respectively. 


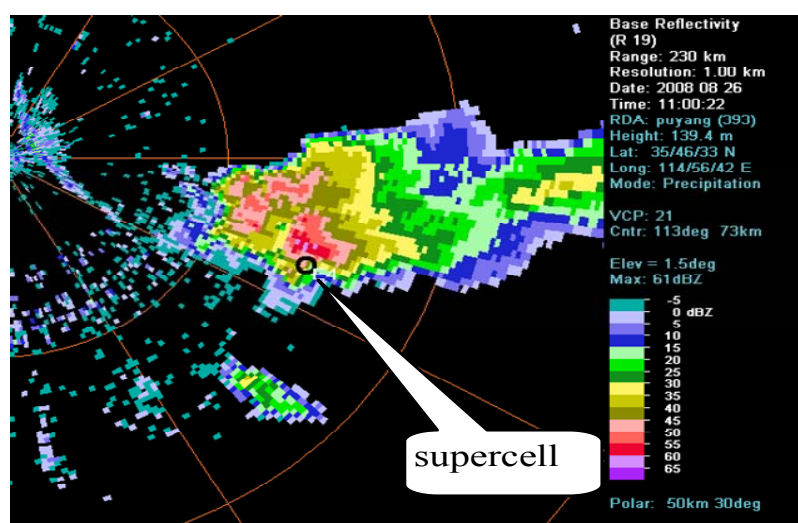

(a)

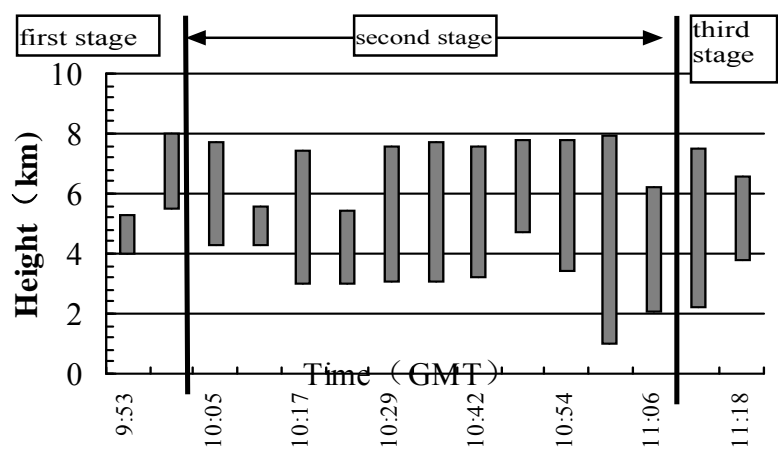

(b)

Figure 1. Low-level reflectivity (a) at 11:00 (GMT) and trend of mesocyclone (b) from 9:53 to 11:18 (GMT) on 26 August 2008, PUYANG radar.

Figure 2 showed an embedded supercell in low-level reflectivity and the trend of mesocyclone. The supercell was embedded in linear convective systems, associated with mesocyclone from 10:30 to $11: 13$ (continuous 8 volume scans). The storm parameters were averaged from 10:30 to $11: 13$. The averaged values of DBZM, C-VIL, HT and TOP for this supercell were $48.9 \mathrm{dBZ}, 15$ $\mathrm{kg} \cdot \mathrm{m}^{-2}, 4.6 \mathrm{~km}$ and $10.0 \mathrm{~km}$ respectively. The first stage of mesocyclone was 10:30 and 10:36 volume scan time, while the third stage was 11:06 and 11:13 volume scan time, and the other volume scan time was the second stage. The averaged values of M-BASE and M-TOP in the three stages were $1.7,0.9,1.4$, and $5.1,6.0,3.9 \mathrm{~km}$ respectively.

The averaged values of M-BASE and M-TOP in the three stages were $3.2,2.1,2.2$ and $5.9,6.6,5.5 \mathrm{~km}$ respectively for two mesocyclones above.

\section{Results}

\subsection{Severe Reports}

There were 54 documented severe weather reports for the 61 supercells. The severe reports consisted of 7 tornado reports, 43 hail reports, 32 large hail reports, 41 damag-

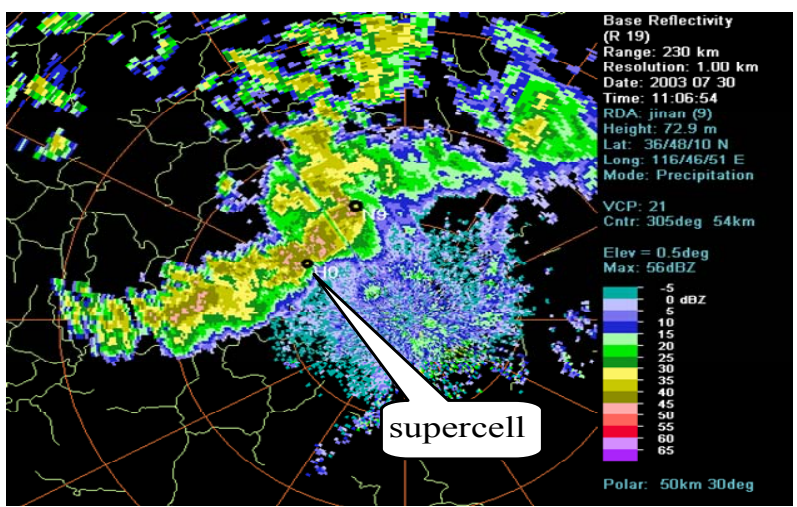

(a)

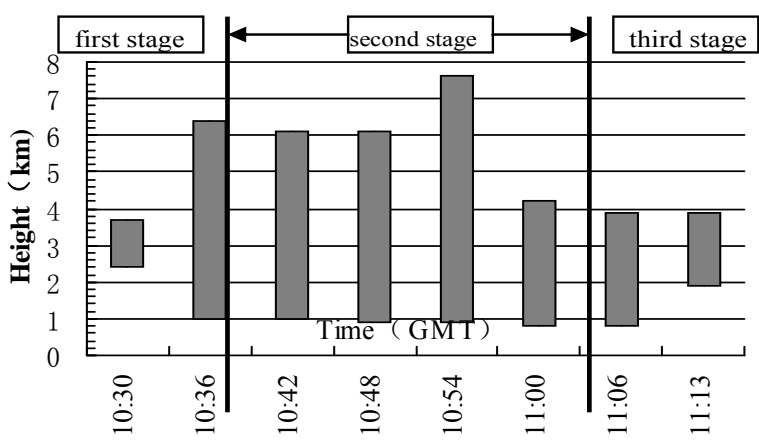

(b)

Figure 2. Low-level reflectivity (a) at 11:06 (GMT) and trend of mesocyclone (b) from 10:30 to 11:13 (GMT) on 30 July 2003, JINAN radar.

ing wind gusts $\left(\geqslant 17.2 \mathrm{~m} \cdot \mathrm{s}^{-1}\right)$ reports and 13 heavy precipitation $\left(\geq 50 \mathrm{~mm} \cdot \mathrm{h}^{-1}\right.$ in this paper) reports. There were two embedded supercells in regions I, one isolated supercell and four embedded supercells in regions II with no severe weather reports.

Detailed severe weather reports for isolated and embedded supercells in different regions are shown in Tables 1 and 2. The probability of producing tornado for supercells in regions II was significantly higher than that in regions I. The probability of hail and large hail occurring for isolated supercells was significantly higher than that for embedded supercells. The probability of gust occurring for embedded supercells was obviously higher than that for isolated supercells. The probability of heavy rain occurring for isolated supercells was higher than that for embedded supercells.

\subsection{Storm Parameters}

Figure 3 showed the storm parameters of supercells and the differences of storm parameters for isolated supercells and embedded supercells in different regions.

The values of storm parameters were significantly higher for type I supercells compared to those for type II supercells. The average values of DBZM, C-VIL, HT, and TOP for type I supercells were $61.6 \mathrm{dBZ}, 53 \mathrm{~kg} \cdot \mathrm{m}^{-2}$, 
Table 1. Severe weather reports for isolated supercells (Type I) in different regions.

\begin{tabular}{cccccc}
\hline & Tornado & Hail & Large hail & Gust & Heavy rain \\
\hline $\begin{array}{c}\text { Reports in } \\
\text { Region I }\end{array}$ & 0 & 15 & 13 & 9 & 4 \\
$\begin{array}{c}\text { Reports in } \\
\text { Region II }\end{array}$ & 3 & 13 & 11 & 10 & 5 \\
$\begin{array}{c}\text { Probability } \\
\text { in Region I }\end{array}$ & 0 & $100 \%$ & $86.7 \%$ & $60.0 \%$ & $26.7 \%$ \\
$\begin{array}{c}\text { Probability } \\
\text { in Region II }\end{array}$ & $17.6 \%$ & $76.5 \%$ & $64.7 \%$ & $58.9 \%$ & $29.4 \%$ \\
\hline
\end{tabular}

Table 2. Severe weather reports for embedded supercells (Type II) in different regions.

\begin{tabular}{cccccc}
\hline & Tornado & Hail & Large hail & Gust & Heavy rain \\
\hline $\begin{array}{c}\text { Reports } \\
\text { in Region I }\end{array}$ & 0 & 8 & 5 & 10 & 2 \\
$\begin{array}{c}\text { Reports } \\
\text { in Region II }\end{array}$ & 4 & 7 & 3 & 12 & 2 \\
$\begin{array}{c}\text { Probability in } \\
\text { Region I }\end{array}$ & 0 & $61.5 \%$ & $38.5 \%$ & $76.9 \%$ & $15.4 \%$ \\
$\begin{array}{c}\text { Probability in } \\
\text { Region II }\end{array}$ & $25.0 \%$ & $43.8 \%$ & $18.9 \%$ & $75.0 \%$ & $12.5 \%$ \\
\hline
\end{tabular}

$5.3 \mathrm{~km}$, and $11.5 \mathrm{~km}$ respectively. The average values of DBZM, C-VIL, HT, and TOP for type II supercells were $58 \mathrm{dBZ}, 39 \mathrm{~kg} \cdot \mathrm{m}^{-2}, 3.9 \mathrm{~km}$, and $10.1 \mathrm{~km}$ respectively.

The values of storm parameters were significantly higher for type I supercells compared to those for type II supercells in region I. The comparison of parameters between type I and type II supercells in region II was the same as that in region I.

The values of storm parameters were somewhat higher for type I supercells in region I compared to those in region II. The average values of storm parameters for type I supercells in region I were $62 \mathrm{dBZ}, 54.7 \mathrm{~kg} \cdot \mathrm{m}^{-2}$, $5.7 \mathrm{~km}$, and $11.8 \mathrm{~km}$ respectively. While those in region II were $61.2 \mathrm{dBZ}, 51.2 \mathrm{~kg} \cdot \mathrm{m}^{-2}, 4.9 \mathrm{~km}$, and $11.2 \mathrm{~km}$ respectively. The values of storm parameters were somewhat higher for type II supercells in region I compared to those in region II.

\subsection{Mesocyclone Parameters and Evolution}

\subsubsection{The Similarities and Differences between Type I Mesocyclone and Type II Mesocyclone}

Figure 4 showed the mesocyclone parameters and the evolution trend during the three stages of mesocyclone for 32 isolated supercells and 29 embedded supercells. The mesocyclones of isolated supercells demonstrated the same evolution trend as the mesocyclones of embedded supercells. The mesocyclone formed in the middle and lower levels of an updraft. The M-BASE obviously

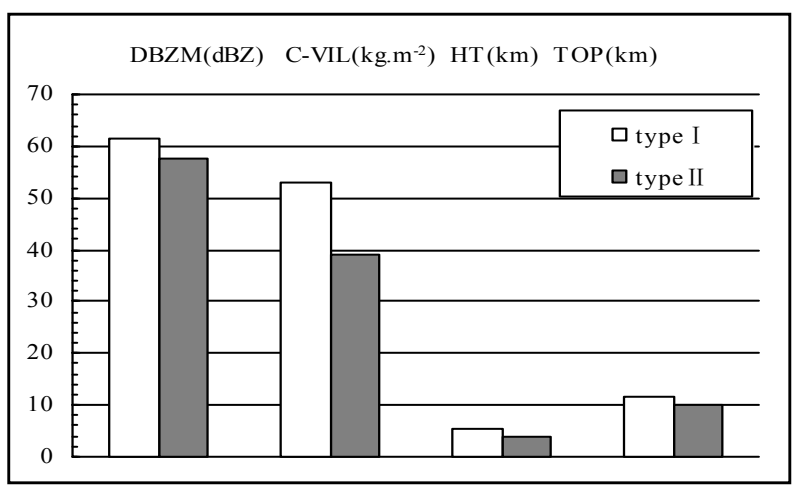

(a)

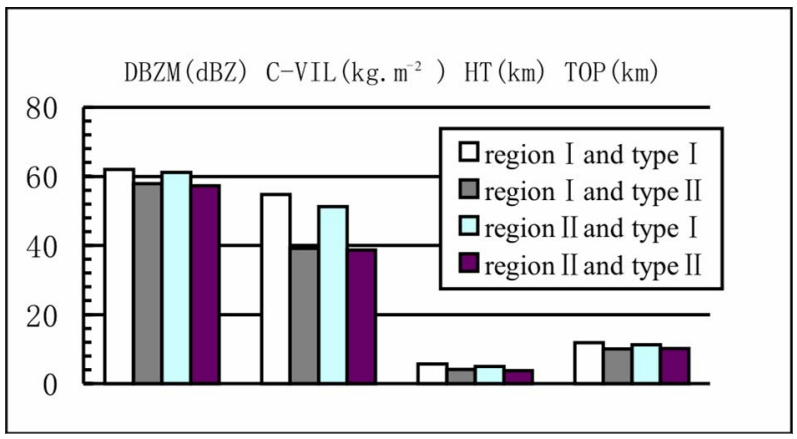

(b)

Figure 3. Type I and type II supercell storm parameters (a), and storm parameters in region I and region II for type I and type II supercells (b).

descended, the M-TOP slightly elevated, the M-DEPTH (height of top minus height of base) and the M-SHEAR obviously increased in the second stage. The M-BASE obviously ascended, the M-TOP slightly descended, the $\mathrm{M}$-DEPTH and the M-SHEAR obviously decreased in the third stage.

The values of M-BASE, M-TOP, M-DEPTH and M-HT for type I supercells were significantly greater than those for type II supercells, while the values of M-SHEAR had almost no differences between type I and type II supercells. The values of M-BASE, M-TOP, $\mathrm{M}$-DEPTH, and M-HT were 2.6, 6.0, 3.4, and $4.6 \mathrm{~km}$ respectively for type I supercells in the second stage, while those were $1.7,4.6,2.9$, and $3.0 \mathrm{~km}$ respectively for type II supercells.

The M-DEPTH was less than $3 \mathrm{~km}$ in the first stage and the third stage for type I and type II supercells, not meeting the vertical extent criteria (shear extends at least $3 \mathrm{~km}$ in the vertical) for mesocyclone. The M-DEPTH in the second stage had met or approached the vertical extent criteria. So, the first stage could be considered as the forming stage, the second stage as the maturing stage, and the third stage as the dissipating stage. Significantly thickening of M-DEPTH and strengthening of M-SHEAR were the important characteristics of a mesocyclone at its mature stage. 


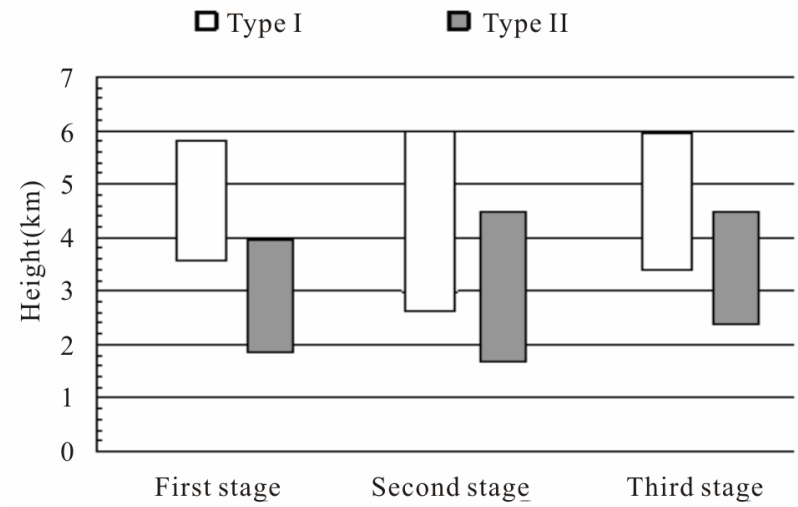

(a)

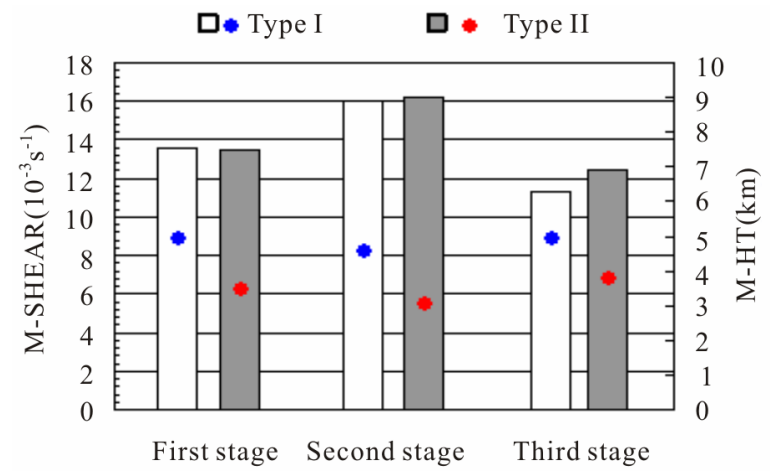

(b)

Figure 4. The trend of the average top and base (a), maximum shear ((b), histogram) and maximum shear height ((b), blue and red punctate) during the three stages of mesocyclone for type I and type II supercells.

\subsubsection{The Similarities and Differences between Type I Mesocyclone and Type II Mesocyclone in Region I}

Figure 5 showed the mesocyclone parameters and the evolution trend during the three stages of mesocyclone for 15 isolated supercells and 17 embedded supercells in region I. The evolution trend of mesocyclones was the same as Figure 4. The values of M-BASE, M-TOP, $\mathrm{M}$-DEPTH, and M-HT were $2.8,6.2,3.3$, and $4.5 \mathrm{~km}$ respectively for type I supercells in the second stage, while those were $1.8,4.5,2.7$, and $3.3 \mathrm{~km}$ respectively for type II supercells.

\subsubsection{The Similarities and Differences between Type I Mesocyclone and Type II Mesocyclone in Region II}

Figure 6 showed the mesocyclone parameters and the evolution trend during the three stages of mesocyclone for 13 isolated and 16 embedded supercells. The evolution trend of mesocyclones was the same as Fig.4. The values of M-BASE , M-TOP, M-DEPTH and M-HT were $2.4,6.2,3.9$ and $4.6 \mathrm{~km}$ respectively for type I supercells in the second stage, while those were 1.5, 4.4,

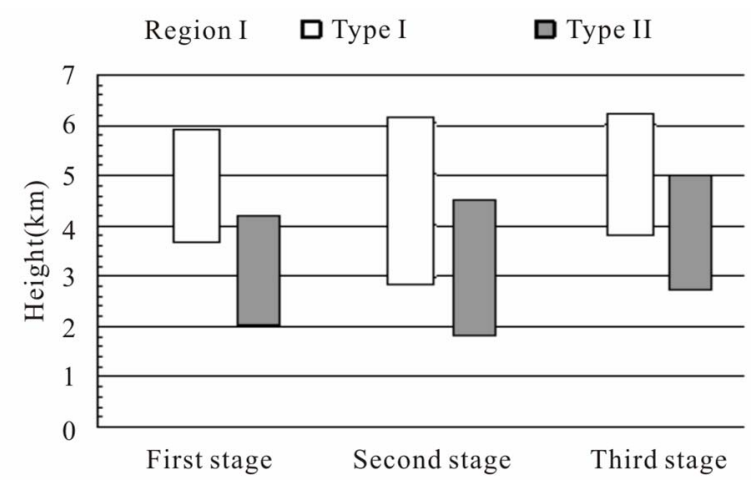

(a)

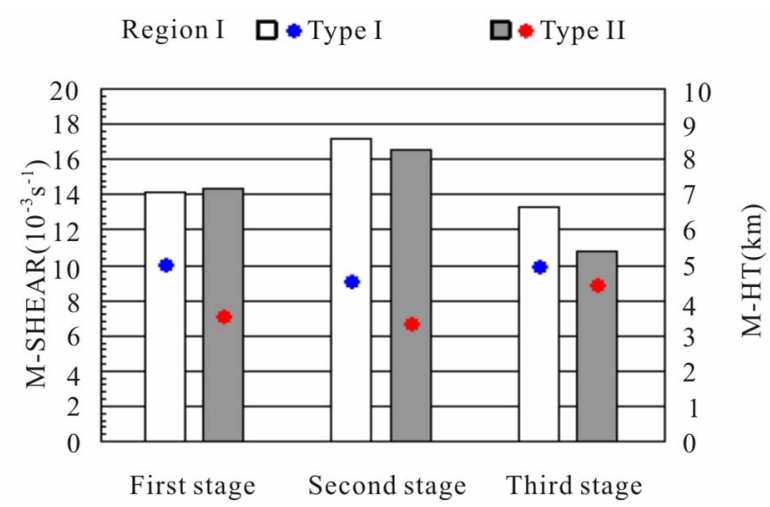

(b)

Figure 5. The trend of the average top and base (a), maximum shear ((b), histogram) and maximum shear height ((b), blue and red punctate) during three stages of mesocyclone for type $I$ and type II supercells in region $I$.

2.9 and $2.9 \mathrm{~km}$ respectively for type II supercells, although the value of M-SHEAR for type II supercells was higher than that for type I supercells in region II.

\subsubsection{The Differences of Mesocyclones between Region I and Region II}

Comparisons of mesocyclone parameters in regionI and region II (Figures 5 and 6) showed that the mesocyclone base in region II was significantly lower than that in region I. The M-BASE for type I and type II supercells in region II was 2.4 and $1.5 \mathrm{~km}$, while in region I that was 2.8 and $1.8 \mathrm{~km}$.

For type I supercells, the average value of M-SHEAR in region II was obviously less than that in region I, especially in the mature stage of mesocyclones. The MSHEAR was $14.8 \times 10^{-3} \mathrm{~s}^{-1}$ in region II while that was $17.3 \times 10^{-3} \mathrm{~s}^{-1}$ in region $\mathrm{I}$ in the mature stage of mesocyclones.

\subsection{Limitation}

1) The B9MA with default algorithm adaptable parameter values in WSR-98D can detect numerous weak, shallow, insignificant circulations. This is partly due to 


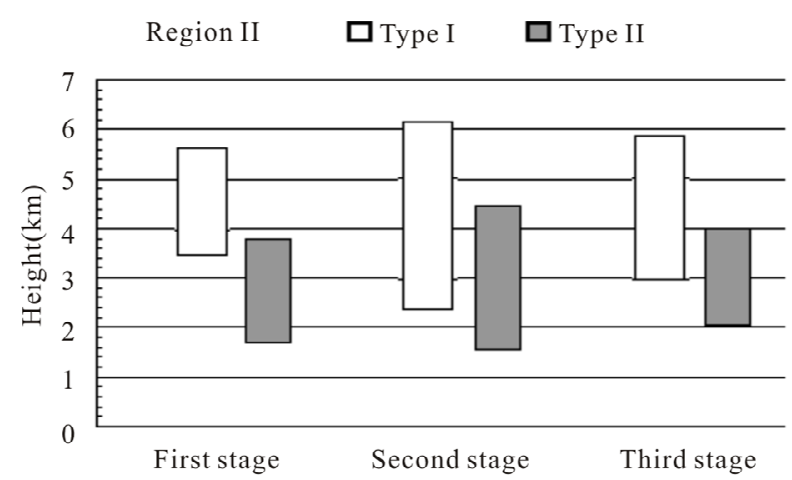

(a)

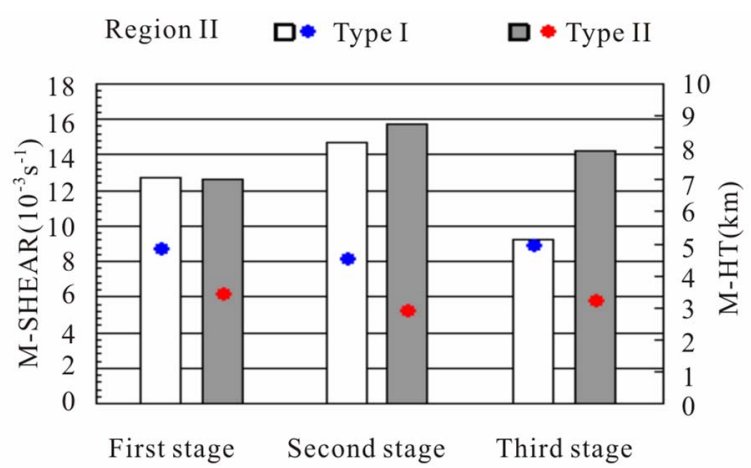

(b)

Figure 6. The trend of the average top and base (a), maximum shear ((b), histogram) and maximum shear height ((b), blue and red punctate) during three stages of mesocyclone for type I and type II supercells in region II.

the fact that circulations do not require a depth of $3 \mathrm{~km}$. This is the limitation of the B9MA but can show evolutionary characteristics of long-lived mesocyclones such as evolution of mesocyclone base and depth.

2) The parameter of mesocyclone strength was not calculated and analysed in this paper. In the mid-1990s, the mesocyclone strength nomogram was used to evaluate manually measurements of observed rotational velocity and range in the United States. Nomogram strength thresholds were based on Oklahoma supercells. In 1995, the integrated rotational strength (IRS index), calculated by summing all 2D rotational strength indices from circulation base to top, was implemented and used. But IRS index has not been applied in WSR-98D. So, there is no parameter of mesocyclone strength in the digital B9MA product. The relationship between mesocyclone strength, storm strength and storm damage could be more complex and needs further research.

3) The results displayed the average statistical characteristics of long-lived mesocyclones, some cases with short-lived mesocyclones may not have similar evolutionary characteristics.

\section{Conclusions}

The storm parameters and severe weather phenomenon had significantly differences between isolated supercells and embedded supercells. The isolated supercell storm parameters such as DBZM, HT, C-VIL, and TOP, were significantly higher than the embedded supercell storm parameters. Isolated supercells had significantly higher probability of hail, large hail and heavy rains, but lower probability of gust than embedded supercells. There was a higher probability of tornado occurrence in the region of Jianghuai Plain.

The mesocyclone parameters had different evolution characteristics in the three stages. The mesocyclone formed in the middle and lower levels of an updraft. The M-BASE obviously descended, the M-TOP slightly ele- vated, the M-DEPTH and the M-SHEAR obviously increased in the mature stage. The M-BASE obviously ascended, the M-TOP slightly descended, the M-DEPTH and the M-SHEAR obviously decreased in the dissipating stage.

The mesocyclone parameter differences between isolated supercells and embedded supercells determined the differences in the reflectivity structure and weather phenomenon. The higher values of M-BASE and M-TOP for isolated supercells indicated that the strong rotating updraft can reach a higher height inside a supercell storm, favorable for the evolution, strength, and longevity of the isolated supercells and for the overhang of high reflectivity core and the growth of large hail. So the isolated supercells had significantly higher probability of hail or large hail.

\section{Acknowledgements}

This work was supported by the National Natural Science Foundation of China (Grant No. 41140036), and the Scientific and Technological Development Projects of Shandong Province (Grant No. 2010GSF10805).

\section{REFERENCES}

[1] K. A. Browning, "Cellular Structure of Convective Storms," The Meteorological Magazine, Vol. 91, No. 1085, 1962, pp. 341-350.

[2] K. A. Browning, "Airflow and Precipitation Trajectories within Severe Local Storms which Travel to the Right of the Winds," Journal of the Atmospheric Sciences, Vol. 21, No. 6, 1964, pp. 634-639. doi:10.1175/1520-0469(1964)021<0634:AAPTWS $>2.0 . C$ $\underline{\mathrm{O} ; 2}$

[3] B. A. Klimowski, M. R. Hjelmfelt, M. J. Bunkers, D. Sedlacek and L. R. Johnson, "Hailstorm Damage Observed from the GOES-8 Satellite: The 5-6 July 1996 Butte-Meade Storm," Monthly Weather Review, Vol. 126, No. 3, 1998, pp. 831-834. 
doi:10.1175/1520-0493(1998)126<0831:HDOFTG>2.0.C $\underline{\mathrm{O} ; 2}$

[4] E. J. Calianese, J. K. Jordan, E. B. Curran, A. R. Moller and G. Woodall, "The Mayfest High-Precipitation Supercell of 5 May 1995-A Case Study," The 21st Conference on Severe Local Storms, San Antonio, 12-16 August 2002, pp. 105-108.

[5] X. G. Diao, J. J. Zhu and Z. H. Liu, "Analysis of Three Supercell Storms with Doppler Weather Radar Data," Acta Meteorologica Sinica, Vol. 25, No. 2, 2011, pp. 211223. doi:10.1007/s13351-011-0028-5

[6] D. W. Burgess, "Single Doppler Radar Vortex Recognition: Part I-Mesocyclone Signatures," The 17th Conference on Radar Meteorology, Seattle, 26-29 October 1976, pp. 97-103.

[7] J. T. Johnson, P. L. MacKeen, A. Witt, E. De Wayne Mitchell, G. J. Stumpf, M. D. Eilts and K. W. Thomas, "The Storm Cell Identification and Tracking (SCIT) Algorithm: An enhanced WSR-88D Algorithm," Weather and Forecasting, Vol. 13, No. 2, 1998, pp. 263-276. doi:10.1175/1520-0434(1998)013<0263:TSCIAT $>2.0 . \mathrm{C}$
$\underline{\mathrm{O} ; 2}$

[8] G. J. Stumpf, A. Witt, E. D. Mitchell, P. L. Spencer, J. T. Johnson, M. D. Eilts, et al., "The National Severe Storms Laboratory Mesocyclone Detection Algorithm for the WSR-88D," Weather and Forecasting, Vol. 13, No. 2, 1998 , pp. 304-326.

doi:10.1175/1520-0434(1998)013<0304:TNSSLM $>2.0 . \mathrm{C}$ $\underline{\mathrm{O} ; 2}$

[9] G. A. Tipton, E. D. Howieson, J. A. Margraf and R. R. Lee, "Optimizing the WSR-88D Mesocyclone/Tornadic Vortex Signature Algorithm Using WATADS-A Case Study," Weather and Forecasting, Vol. 13, No. 2,1998, pp. $367-376$.

doi:10.1175/1520-0434(1998)013<0367:OTWMTV>2.0. $\mathrm{CO} ; 2$

[10] B. T. Smith, J. L. Guyer and A. R. Dean, "The Climatology, Convective Mode, and Mesoscale Environment of Cool Season Severe Thunderstorms in the Ohio and Tennessee Valleys, 1995-2006," The 24th Conference on Severe Local Storms, Savannah, 27-31 October 2008. http://ams.confex.com/ams/pdfpapers/141968.pdf 